\title{
Metagenomic 16s rRNA investigation of microbial communities in the Black Sea estuaries in South-West of Ukraine*\#
}

\author{
Oleksandra Bobrova ${ }^{\circledR}$, Jon Bent Kristoffersen², Anastasis Oulas² and Volodymyr Ivanytsia \\ 'Department of Microbiology, Virology and Biotechnology, Odessa National I. I. Mechnikov University, Odessa, Ukraine; 2Institute of Marine Biol- \\ ogy, Biotechnology and Aquaculture, Hellenic Centre for Marine Research, Heraklion, Greece
}

The Black Sea estuaries represent interfaces of the sea and river environments. Microorganisms that inhabit estuarine water play an integral role in all biochemical processes that occur there and form unique ecosystems. There are many estuaries located in the Southern-Western part of Ukraine and some of them are already separated from the sea. The aim of this research was to determine the composition of microbial communities in the Khadzhibey, Dniester and Sukhyi estuaries by metagenomic 16S rDNA analysis. This study is the first complex analysis of estuarine microbiota based on isolation of total DNA from a biome that was further subjected to sequencing. DNA was extracted from water samples and sequenced on the Illumina Miseq platform using primers to the V4 variable region of the 16S rRNA gene. Computer analysis of the obtained raw sequences was done with QIIME (Quantitative Insights Into Microbial Ecology) software. As the outcome, 57970 nucleotide sequences were retrieved. Bioinformatic analysis of bacterial community in the studied samples demonstrated a high taxonomic diversity of Prokaryotes at above genus level. It was shown that majority of $16 \mathrm{~S}$ rDNA bacterial sequences detected in the estuarine samples belonged to phyla Cyanobacteria, Proteobacteria, Bacteroidetes, Actinobacteria, Verrucomicrobia, Planctomycetes. The Khadhzibey estuary was dominated by the Proteobacteria phylum, while Dniester and Sukhyi estuaries were characterized by dominance of Cyanobacteria. The differences in bacterial populations between the Khadzhibey, Dniester and Sukhyi estuaries were demonstrated through the Beta-diversity analysis. It showed that the Khadzhibey estuary's microbial community significantly varies from the Sukhyi and Dniester estuaries. The majority of identified bacterial species is known as typical inhabitants of marine environments, however, for $2.5 \%$ of microbial population members in the studied estuaries no relatives were determined.

Key words: prokaryotic diversity, Black Sea estuaries, 16S rDNA analysis, metagenomic analysis

Received: 30 July, 2015; revised: 24 November, 2015; accepted: 15 January, 2016; available on-line: 29 February, 2016

\section{INTRODUCTION}

Bacterial communities that inhabit water environments play an important role in all biogeochemical processes occurring there. They are the integral part of a marine ecosystem and are the basis of trophic food web networks. Metagenomic investigations helped to estimate prokaryotic microorganisms' distribution, their taxonomic diversity and functional gene content (Venter et al., 2004; Schauer et al., 2010), and evaluate their role in biogeochemical processes (DeLong \& Karl, 2005).

The Black Sea and its estuaries form a unique marine ecosystem with rich microbial community that influences all biogeochemical processes that take place in the oxygen-containing surface and anoxic bottom layers. Nevertheless the bacterial diversity of the Black Sea is yet underestimated. Even though a few metagenomic $16 \mathrm{~S}$ rDNA investigations of the Black Sea water had shed some light on the taxonomic composition of marine microorganisms (Vetriani et al., 2003; Fuchsman et al., 2011), the microbial composition of the freshwater estuaries that are tightly connected with the Black Sea remains almost unknown.

The estuaries vary from each other by their environmental conditions. Dniester estuary is connected with the Black Sea in its southern part. The full- flowing Dniester river flows into the sea's eastern part. This is one of the biggest open basins in Ukraine. The Sukhyi estuary is also connected with the sea by means of a navigable channel and specifically presents itself as a marine harbor. A shallow, drying Dalnyk river flows in at the northern part of this estuary. The port of Illichivsk is situated at the right coast of the estuary in its southern part. The Khadzhibey estuary, previously connected with the sea, today is separated from it by a sand dam and has no connection with the sea.

The aim of our study was to obtain complex information about the biodiversity of microbial communities in the waters of the Dniester, Sukhyi and Khadzhibey estuaries, by metagenomics $16 \mathrm{~S}$ rDNA analysis. Here, we provide comparative analysis of the three sampled regions, as well as comparison with other public data from similar environments. Observations from the studied samples suggest different taxonomic composition between samples, depending on the environmental status.

\section{MATERIALS AND METHODS}

For analysis of microbial diversity, the water samples were collected from three Black Sea estuaries, called hereafter Dniester (Dnst), Sukhyi (Sukh) and Khadzhibey (Khad), with the following coordinates: Dnst 46.073248, 30.454627; Sukh — 46.352112, 30.647934; and Khad - 46.548585, 30.651366 (Fig. 1).

\footnotetext{
e-mail: o.bobrova@onu.edu.ua
}

*The results were presented at the 6th International Weigl Conference on Microbiology, Gdańsk, Poland (8-10 July, 2015).

"Study accession number in ENA — PRJEB9914

Abbreviations: ENA, European nucleotide archive; Dnst, Dniester estuary; Khad, Khadzibey estuary; QIIME, Quantitative Insights Into Microbial Ecology; Sukh, Sukhyi estuary 


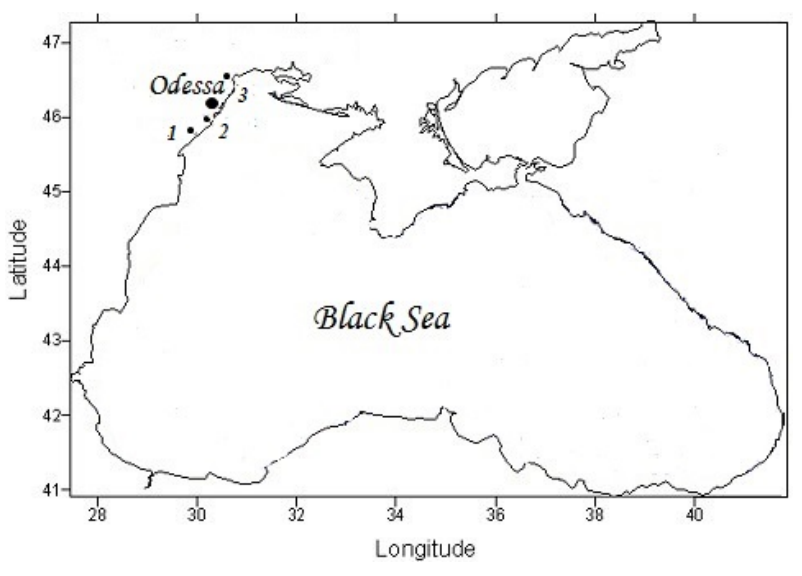

Figure 1. Scheme showing the sampling sites in the estuaries. Dniester estuary (Dnst) -1 , Sukhyi estuary (Sukh) -2 , Khadzhibey estuary (Khad) -3 .

Samples were collected in July of 2014, in sterile glass bottles at a $1 \mathrm{~m}$ depth from the surface. Water was filtered through $0.22 \mu \mathrm{m}$ membrane filters (Sartorius). At each station, the $\mathrm{pH}$ and temperature were measured.

Isolation of the nucleic acids from microorganisms collected by filtration was performed with the Power Water DNA isolation kit (MO BIO Laboratories). The DNA extraction procedure was performed as described by the manufacturer. Size of the extracted DNA was evaluated by an agarose gel electrophoresis.

Primer design followed the one described by Kozich and coworkers (2013), who modified the single-index method by Caporaso and coworkers (2012) to a more efficient dual index approach. Each PCR primer consisted of the appropriate Illumina adapter, index sequence, pad sequence, linker and the $16 \mathrm{~S}$ rDNA V4 variable region specific primer pair 515f, 806r. This yielded an insert fragment of about 253 bp. The complete amplified product by those primers was around $387 \mathrm{bp}$.

PCR reactions were performed using KAPA HiFi HotStart PCR kits (Kapa Biosystems). Each PCR reaction contained $0.2 \mathrm{M}$ Trehalose, $5 \mu$ Fidelity buffer, $0.75 \mu \mathrm{K}$ KAPA dNTP mix, $0.3 \mu \mathrm{M}$ of the forward and reverse primers, 0.5 units KAPA HiFi polymerase, about $25 \mathrm{ng}$ template DNA, and PCR grade water added up to $25 \mu \mathrm{l}$. Thermal cycling conditions were as follows: $95^{\circ} \mathrm{C}$ for $3 \mathrm{~min}$, followed by 27 cycles of $98^{\circ} \mathrm{C}$ for $20 \mathrm{~s}, 61^{\circ} \mathrm{C}$ for $10 \mathrm{~s}$, and $72^{\circ} \mathrm{C}$ for $15 \mathrm{~s}$. A final extension step was performed at $72^{\circ} \mathrm{C}$ for $5 \mathrm{~min}$.

The PCR products were purified with AMPure XP magnetic beads (Beckman Coulter) and quantified with the Quant-iT PicoGreen dsDNA Assay Kit (Life Technologies) and a plate fluorimeter (QuantiFluor). The final pool of thus obtained 16S rDNA amplicon library was quantified with a KAPA Universal qPCR kit (Kapa Biosystems) before the sequencing run.

Sequencing was performed on an Illumina MiSeq platform. Reads of low quality were discarded and trimmed from the dataset. The PEAR tool (Zhang et al., 2013) was used for merging the overlapping pair end data and generation of assembled read files. The bioinformatics analysis of the assembled reads was performed with QIIME (Quantitative Insights Into Microbial Ecology) software, version 1.8.0 (Caporaso et al., 2010) which seems to be the "gold standard" for analysis of the $16 \mathrm{~S}$ rDNA matagenomic datasets (Nilakanta H. et al., 2014).
Table 1. Environmental parameters of the sampling stations

\begin{tabular}{|c|c|c|c|}
\hline \multirow{2}{*}{ Station samples } & \multicolumn{3}{|c|}{ Parameters of water } \\
\hline & Salinity (\%o) & $\mathrm{pH}$ & Temperature $\left({ }^{\circ} \mathrm{C}\right)$ \\
\hline Khad & 5.5 & 8.75 & 25 \\
\hline Sukh & 10 & 8.48 & 25 \\
\hline Dnst & 13 & 8.35 & 24 \\
\hline
\end{tabular}

\section{RESULTS}

The environmental parameters that were evaluated showed that the most significant gradient between the three studied estuaries was salinity (Table 1), which reached the highest value for the Dniester sample and the lowest for Khadzibey. Temperature and $\mathrm{pH}$ measurements did not significantly vary between samples.

After sequencing and further processing, 57970 sequences remained that belonged to the studied water samples of Khad, Sukh and Dnstr. Demultiplexing was done automatically by the MiSeq Reporter software at the completion of the sequencing run. The nucleotide sequences were deposited at the European $\mathrm{Nu}$ cleotide Archive (ENA) under study accession number PRJEB9914.

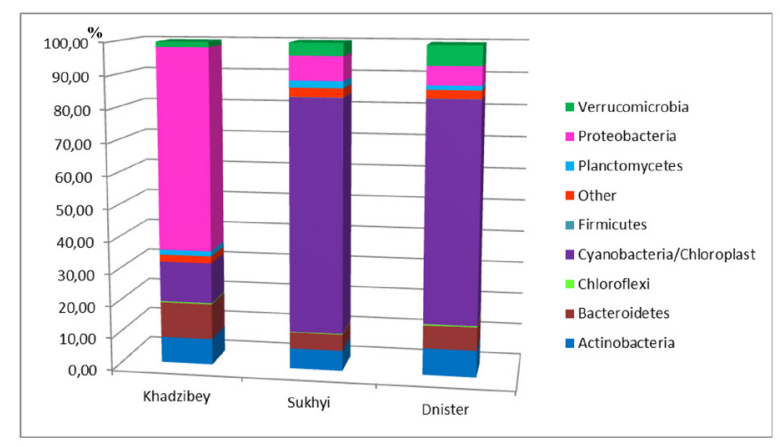

Figure 2. Bar charts represent the taxonomic distribution of phylogenetic groups at the phylum level.

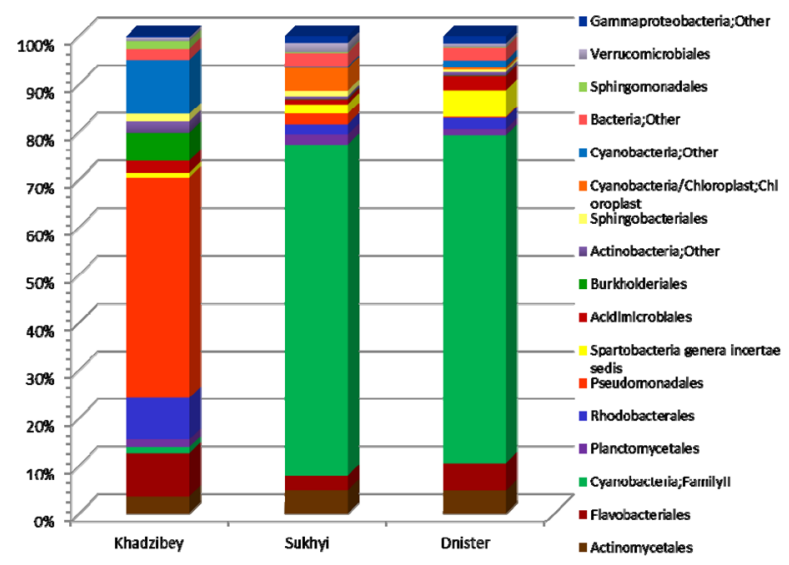

Figure 3. Bar charts represent the taxonomic distribution of phylogenetic groups at the order level among studied estuaries 


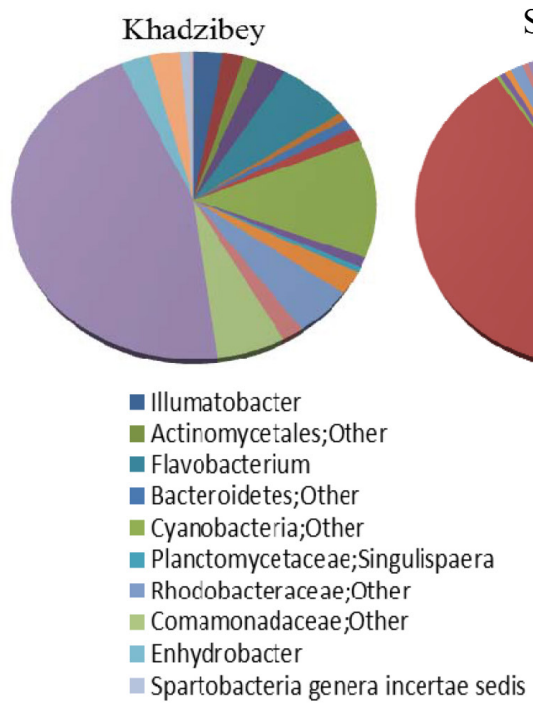

Sukhyi

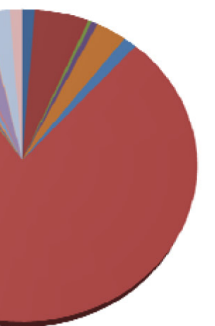

Microbacteriaceae;Other

- Actinobacteria;Other

- Flavobacteriaceae;Other

- Cyanobacteria;Familyll;Gplla

- Planctomycetaceae; Rhodopirellula

Marivita

- Phaeobacter

Acinetobacter

- Pseudomonas

Prosthecobacter

\section{Figure 4. Diagrams representing the taxonomy composition among studied samples}

$16 \mathrm{~S}$ rDNA gene analysis of the three samples identified representatives of 8 bacterial phyla. The results of phylogenetic analysis were temperately concordant, especially between the Sukh and Dnst samples, where we observed the same dominance of bacterial phyla representatives (Fig. 2). Thus, the majority of the bacterial sequences found in the water of Sukh and Dnstr estuaries belonged to the Cyanobacteria phylum $(72.2 \%$ and $68 \%$, respectively). The principal difference in the dominating phyla composition between the studied samples, is that the Proteobacteria representatives (62.4\%) prevailed in the Khad sample. Also, a lower amount of the Khad sequences were affiliated with the Cyanobacteria phylum $(12.6 \%)$.

At the same time, Proteobacteria were the second dominating phylum in the Sukh and Dnst samples $(7.4 \%$ and $5.7 \%$, respectively). The Proteobacteria and Cyanobacteria phyla were followed by representatives of Bacteroidetes (Khad - 11.1\%, Sukh $-5.1 \%$, Dnst $-7.2 \%$ ), Actinobacteria (Khad - 8.1\%, Sukh - 6.3\%, Dnst $7.2 \%$ ), Verrucomicrobia (Khad - 1.6\%, Sukh - 3.9\%, Dnst - 6.1\%), Planctomycetes (Khad - 1.6\%, Sukh $2.1 \%$, Dnst - 1.3\%), Chloroflexi (Khad - 0.3\%, Sukh - 0.2\%, Dnst - 0.4\%) and Firmicutes (Sukh - 0.1\%, Dnst $-0.1 \%)$.

The majority of bacterial sequences identified as Proteobacteria belonged to the Gammaproteobacteria and Alphaproteobacteria. In contrast, Betaproteobacteria were mainly present in the Khad sample, and corresponded to a low number of sequences found in both, the Sukh and Dnst estuaries. Only slight traces of the Deltaproteobacteria class representatives were discerned, while Epsilonproteobacteria members were not detected at all among the studied samples.

Analysis at the taxonomic level of the "order" with the most numerous representatives is shown on Fig. 3. It is demonstrated, that Family II of Cyanobacteria amounted to $67.1 \%$ and $65.9 \%$ in the Sukh and Dnst samples, respectively, and $0.2 \%$ in the Khad sample. At the same time, the Khad sample was dominated by representatives of the Pseudomonadales order $(43.8 \%)$. Members of this order were detected in low amounts in the water from the Sukh and Dnst estuaries $(2.2 \%$ and $0.2 \%$, respectively). The next predominant orders were the following: Rhodobacteriales (Khad - 8.2\%, Sukh - 2.0\%, Dnst - 2.2\%), Flavobacteriales (Khad - 8.6\%, Sukh - 3.0\%, Dnst - 5.5\%), Actinomycetales (Khad - 3.3\%, Sukh - 4.7\%, Dnst - 4.6\%), Acidimicrobiales (Khad $-2.4 \%$, Sukh - 1.0\%, Dnst $2.9 \%$ ), Planctomycetales (Khad - 1.6\%, Sukh - 2.1\%, Dnst - 1.3\%), Burkholderiales (Khad - 5.5\%, Sukh $0.1 \%$, Dnst - $0.1 \%$ ), and members of the Spartobacteria class (Khad - $0.9 \%$, Sukh - 1.9\%, Dnst - 5.3\%).

The taxonomic composition at the genus level is shown on diagrams (Fig. 4). Acinetobacter is the dominating genus in the Khad sample, whereas Sukh and Dnst are dominated by Actinobacteria. Representatives of Rhodobacteriaceae, Comamonadaceae, Flavobacterium, Pseudomonas, Marivita, Phaeobacter, Enhydrobacter and others were also

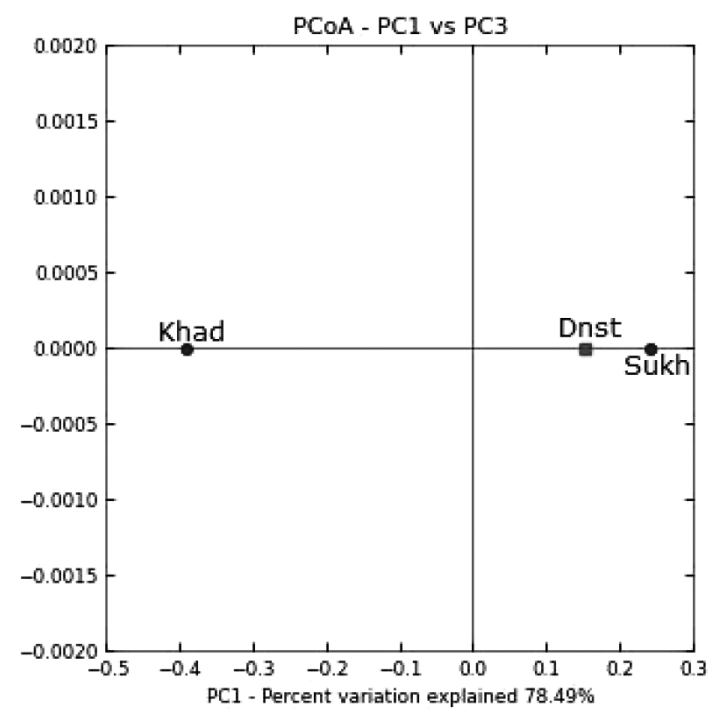

Figure 5. Principal coordinate from a PCA of the estuarine samples.

The percentage on the axis labels represents the percentage of variation explained by the principal coordinates. Each axis indicates the fraction of the variance in the data that the axis accounts for. 
observed for the Khad sample; on the other hand, representatives of Cyanobacteria, Actinobacteria, Planctomycetaceae, Spartobacteria, Marivita, Phaeobacter, Acinetobacter, and Prosthecobacter were observed for the Sukh and Dnst samples.

The community analysis of the studied samples was performed at the detected OTUs' level in the QIIME pipeline (Fig. 5). Beta-diversity estimates the differences in microbial communities between samples by calculating the "distance" between each pair of community samples. The output file of beta-diversity step with matrix of differences is then visualized through Principal Coordinates Analysis (PCoA). It demonstrates that the Sukh and Dnst samples are clustered together, separately from the Khad, depending on the Prokaryotes' diversity (Fig. 5).

\section{DISCUSSION}

This investigation provides new insights into the microbial biodiversity of the Black Sea freshwater estuaries. The results of phylogenetic analysis based on the $16 \mathrm{~S}$ rDNA revealed a rich microbial community in the waters of the Sukhyi, Dniester and Khadzhibey estuaries and point out that there are clear differences in the community structures between samples regarding the dominant taxa. The Khadzibey estuary was abundant in Proteobacteria, where Gammaproteobacteria, Alphaproteobacteria and Betaproteobacteria were the most represented classes. Similar results were obtained by us for the water around Zmijiniy Island (Bobrova et al., 2015), where the same correlation of dominating phylum with its classes was observed. The distribution of the dominating taxonomic phyla and classes in the Khadzibey estuary is very similar to the results of the Sargasso Sea investigation (Venter et al., 2004) and the study of the Changjiang estuary in China (Feng et al., 2009), with the only difference being that Betaproteobacteria are the most abundant class there, after Gammaproteobacteria. Despite low salinity in the Khadzibey estuary, it is still characterized by a more typical marine distribution (Alphaproteobacteria dominating), while Betaproteobacteria are commonly detected in freshwater lakes (Mueller-Spitz et al., 2009).

The Sukhyi and Dniester estuaries were characterized by prevalence of the Cyanobacteria phylum. These microorganisms are commonly found in freshwater environments. It is suggested that climate warming leads to an increase in their quantity in the European water reservoirs (Pitois et al., 2014). The anthropogenic pressure also seems to be one of the factors that lead to an increase in Cyanobacteria populations in the marine environments.

Bacterial representatives of the Bacteroidetes phylum were highly represented in all three estuarine samples, approximately in equal quantities with the dominating Flavobacteria genus. In the water environments, some members of the Bacteroidetes usually live in symbiosis with algae. A similar moderate distribution of Bacteroidetes and its dominating genus Flavobacteria was observed in the Sargasso Sea investigation (Veinter et.al., 2004). But in contrast to our results, a significant presence of another Bacteroidetes genus - Bacteroides, that used to be grouped in one CFB phylum (Cytophaga, Flavobacterium, Bacteroides), was observed in the Sargasso Sea. The Bacteroides members were not detected among estuarine samples studied here.

Actinobacteria are present in significant amounts among all studied estuaries. These microorganisms are known as producers of many bioactive compounds, like actino- mycin and antibiotics. Actinobacteria have been found in deep-ocean sediments worldwide. Recently, marine Actinobacteria strains were isolated from the Adyar estuary and the Royapuram, Muttukadu, Mahabalipuram sea shores by Valli and coworkers (2012), and were shown to be a potent source of novel antibiotics.

Acinetobacter representatives are found in large amounts in the Khadzibey estuary. The Acinetobacter genus is phylogenetically related to the Gammaproteobacteria, and the Moraxellaceae family. They are widely distributed in nature, including soil and water, sewage, human clinical specimens, and activated sludge (Yoon et al., 2007). The members of this genus are typical soil inhabitants playing a role in the mineralization process. However, some species are known to be pathogenic.

All estuarine samples were characterized by a relatively high presence of Planctomycetes. This phylum includes all known Anaerobic Ammonium Oxidizing bacteria (Anammox bacteria) that are more typically found in sediments than as free living organisms in surface waters. This data coincides with studies of the Black Sea by Kirkpatrick and coworkers (2006) and Fuchsman and coworkers (2012). Representatives of Planctomycetes were also detected in the water around Zmijiniy Island (Bobrova et al., 2015), however, in lower amounts.

Members of the Spartobacteria class were also diverse among all three studied samples. These bacteria belong to the Verrucomicrobia phylum and are one of the most dominant species within soil environment communities (Bergmann et al., 2012). They are difficult to cultivate and as a result they are poorly represented in public databases. Verrucomicrobia were prevalent in the sediment samples from the Changjiang estuary (Feng et al., 2009). However, these bacteria were recently reported by Freitas and coworkers (2012) to be ubiquitous in the water columns, and suggested to be important for the biogeochemical cycle of carbon in the ocean.

Members of the Chloroflexi phylum were observed only in slight amounts among the studied samples. These representatives have been recovered from different environments, but they are especially highly diverse in the aquifer sediments, playing a key role in sediment carbon cycling (Hug et al., 2013).

Majority of the detected bacteria are known and described as typical inhabitants of the marine environments. However, no relatives were found for $2.5 \%$ of the microbial communities' members among the studied estuaries. Here, they were annotated as "Others". This group includes species for which little information is known or the information is absent in reference Greengenes database (http://greengenes.secondgenome. com). The use of another reference database, like Silva, would probably help in taxonomic assignment of at least a part of marine microorganisms belonging to this group because Silva is specialized in $16 \mathrm{~S}$ rDNA gene sequences obtained from marine samples.

The beta-diversity analysis provided here, demonstrates the similarity of microbial communities' distribution in the Sukhyi and Dniester estuaries, and their significant difference from the Khadzhibey estuary. It seems that salinity is one of the main agents in bacterial distribution among different marine samples (Sun et.al., 2009). In our study, it was shown that a sample from the Khadzibey estuary with lower salinity (5.5\%) clusters separately from the other samples (Sukh - 10\%o, Dnst - 13\%0) with higher salinity measurements. Another significant factor that influences the microorganisms' biological diversity can be the estuary connection to the sea, freshwater flow from the rivers into the Sukhyi and 
Dniester estuaries and isolation of the Khadzhibey estuary from the Black Sea.

In conclusion, the results of investigation provided here give complex information about the biodiversity of microbial communities in the Black Sea estuaries. The 16S rDNA sequences were analyzed with bioinformatics tools to assess taxonomic composition of bacterial community in this environment. Differences and similarities were demonstrated through beta-diversity. Higher bacterial diversity was observed in the Khadzibey estuary. However, in general the results of this investigation are concordant with previous observations of the Black Sea in this area. Environmental factors, such as salinity and connection to the sea, that influence biodiversity were described. This comparative metagenomics analysis enhances our understanding of microbial ecology of the Black Sea estuaries located in the Odessa region of Ukraine. It gives an opportunity to understand the microbial diversity of these basins and answer the question "Who is there?".

\section{Acknowledgements}

The authors greatly appreciate assistance and support received from Dr. Georgios Kotoulas and Dr. Antonios Magoulas from the institute of Marine Biology, Biotechnology and Aquaculture (IMBBC), Hellenic Centre for Marine Research (HCMR).

\section{REFERENCE}

Bergmann GT, Bates ST, Eilers KG, Lauber CL, Caporaso JG, Walters W, Knight R, Fierer N (2012) The under-recognized dominance of Verrucomicrobia in soil bacterial communities. Soil Biol Biochem 43: 1450-1455. http://dx.doi.org/10.1016/j.soilbio.2011.03.012.

Bobrova OE, Kristofferssen J, Ivanytsia VO (2015) Metagenome $16 \mathrm{~S}$ rRNA gene analysis of the Black Sea microbial diversity in the region of the Zmiiniy Island. Microbiol \& Biotechnol 2: 6-19.

Caporaso JG et al (2012) Ultra-high-throughput microbial community analysis on the Illumina HiSeq and MiSeq platforms. The ISME J 6: 1621-1624. http://dx.doi.org/10.1038/ismej.2012.8.

Caporaso JG, Kuczynski J, Stombaugh J, Bittinger K, Bushman FD, Costello EK, Fierer N (2010) QIIME allows analysis of highthroughput community sequencing data. Nature Methods 7: 335-336. http://dx.doi.org/ 10.1038/nmeth.f.303.

DeLong EF, Karl DM (2005) Genomic perspectives in microbial oceanography. Nature 437: 336-342. http://dx.doi.org/10.1038/nature 04157 .

Feng B, Li X, Wang J, Hu Z, Meng H, Xiang L, Quan Z. (2009) Bacterial diversity of water and sediment in the Changjiang estuary and coastal area of the East China Sea. FEMS Microbiol Ecol 70: 236248. http://dx.doi.org/10.1111/j.1574-6941.2009.00772.x.

Freitas S, Hatosy S, Fuhrman JA, Huse SM, Welch DB, Sogin ML, Martiny AC (2012) Global distribution and diversity of ma- rine Verrucomicrobia. The ISME J 6: 1499-1505. http://dx.doi. org/10.1038/ismej.2012.3.

Fuchsman CA, Kirkpatrick JB, Brazelton WJ, Murray JW, Staley JT (2011) Metabolic strategies of free-living and aggregate-associated bacterial communities inferred from biologic and chemical profiles in the Black Sea suboxic zone. FEMS Microbiol Ecol 78: 586-603. http://dx.doi.org/10.1111/j.1574-6941.2011.01189.x.

Fuchsman CA, Staley JT, Oakley BB, Kirkpatrick JB, Murray JW (2012) Free-living and aggregate-associated Planctomycetes in the Black Sea. FEMS Microbiol Ecol 80: 402-416. http://dx.doi. org/10.1111/j.1574-6941.2012.01306.x.

Hug L, Castelle C, Thomas B, Sharon I, Frischkorn K, Williams K, Tringe S, Banfield J (2013) Community genomic analyses constrain the distribution of metabolic traits across the Chloroflexi phylum and indicate roles in sediment carbon cycling. Microbiome 1: 22. http://dx.doi.org/10.1186/2049-2618-1-22.

Kirkpatrick J, Oakley B, Fuchsman C, Srinivasan S, Staley JT, Murray JW (2006) Diversity and distribution of planctomycetes and related bacteria in the suboxic zone of the Black Sea. Appl Environ Microbiol 72: 3079-3083. http://dx.doi.org/10.1128/AEM.72.4.

Kozich JJ, Westcott SL, Baxter NT, Highlander SK, Schloss PD (2013) Development of a dual-index sequencing strategy and curation pipeline for analyzing amplicon sequence data on the MiSeq Illumina sequencing platform. Appl Environ Microbiol 17: 5112-5120. http:// dx.doi.org/10.1128/AEM.01043-13.

Navas-Molina J et al. (2013) Advancing our understanding of the human microbiome using QIIME. Methods Enzymol 531: 371-444. http://dx.doi.org/10.1016/B978-0-12-407863-5.00019-8.

Nilakanta H, Drews KL, Firrell S, Foulkes MA, Jablonski KA (2014) A review of software for analyzing molecular sequences. BMC Res Notes 7: 830-830. http://dx.doi.org/10.1186/1756-0500-7-830.

Pitois F, Thoraval I, Baurès E, Thomas O (2014) Geographical patterns in cyanobacteria distribution: climate influence at regional scale. Toxins 6: 509-522. http://dx.doi.org/10.3390/toxins6020509.

Schauer R, Bienhold C, Ramette A, Harder J (2010) Bacterial diversity and biogeography in deep-sea surface sediments of the South Atlantic Ocean. The ISME J 4: 159-170. http://dx.doi.org/10.1038/ ismej.2009.106.

Sun T, Yang ZF, Shen ZY, Zhao R (2009) Environmental flows for the yangtze estuary based on salinity objectives. Commun Nonlinear Sci Numer Simul 14: 959-971. http://dx.doi.org/10.1016/j.cnsns.2007.10.006.

Valli S, Suvathi SS, Aysha OS, Nirmala P, Vinoth KP (2012) Antimicrobial potential of Actinomycetes species isolated from marine environment. Asian Pacific J Tropical Biomed 2: 469-473.http://dx.doi. org/10.1016/S2221-1691(12)60078-1.

Venter JC et al. (2004) Environmental genome shotgun sequencing of the Sargasso Sea. Science 304: 66-74. http://dx.doi.org/10.1126/science.1093857.

Vetriani C, Tran HV, Kerkhof LK (2003) Fingerprinting microbial assemblages from the oxic/anoxic chemocline of the Black Sea. Appl Environ Microbiol 69: 6481-6488. http://dx.doi.org/10.1128/ AEM.69.11.

Yoon, Jung-Hoon, Kim, Tae-Kwang Oh J (2007) Acinetobacter marinus sp. nov. and Acinetobacter seobaensis sp. nov, Isolated from Sea Water of the Yellow Sea in Korea. Microbiol Biotechnol 17: 1743-1750.

Zhang J, Kobert K, Fluori T, Stamatakis A (2013) PEAR: a fast and accurate illumina paired-end read merger. Bioinformatics 30: 614-620. http://dx.doi.org/ 10.1093/bioinformatics/btt593. 